\title{
Granular FePt-Ag thin films with uniform FePt particle size for high-density magnetic recording
}

\author{
S.-C. Chen *, P.C. Kuo, A.C. Sun, C.T. Lie, W.C. Hsu \\ Institute of Materials Science and Engineering, National Taiwan University, Taipei, Taiwan, ROC
}

Received 4 September 2001; accepted 20 October 2001

\begin{abstract}
The granular $\mathrm{FePt}-\mathrm{Ag}$ thin films consisting of $\mathrm{FePt}$ particles dispersed in a $\mathrm{Ag}$ matrix were prepared by co-sputtering from $\mathrm{FePt}$ and $\mathrm{Ag}$ targets. The FePt particles in as-deposited film are soft magnetically disordered face-centered-cubic $\gamma$-FePt phase. The magnetic easy-direction of the as-deposited film is parallel to the film plane. The in-plane coercivities of the as-deposited films were below 700 Oe. The higher coercivity of the film will obtain after annealed treatment by transforming the $\gamma$-FePt phase into hard magnetically ordered face-centered-tetragonal (fct) $\gamma_{1}$-FePt phase. The in-plane coercivity of the annealed film was much larger than out-plane coercivity. The particle size of $\mathrm{FePt}$ in annealed film was increased with annealing temperature but decreased with increasing $\mathrm{Ag}$ content. The $(\mathrm{FePt})_{70}-(\mathrm{Ag})_{30}$ film with film thickness of $10 \mathrm{~nm}$ annealed at $600{ }^{\circ} \mathrm{C}$ for $15 \mathrm{~min}$ and ice-water quenched having an in-plane coercivity around $3.5 \mathrm{kOe}$. The $M_{\mathrm{s}}$ value of this film is about $350 \mathrm{emu} \mathrm{cm}{ }^{-3}$ and the squareness is about 0.8. The FePt particle size in this film was very uniform and the FePt particles were isolated by Ag. (C) 2002 Elsevier Science B.V. All rights reserved.
\end{abstract}

Keywords: Cosputtering; Granular FePt-Ag thin film; Magnetic properties

\section{Introduction}

For high density magnetic recording thin film, the magnetic grains must be small enough to be nanoparticle size and also requires that uniform size and isolated magnetic particles to reduce intergrain interaction, which leads to lower media noise [1-3]. However, small particle size will result in smaller $K_{\mathrm{u}} V / K_{\mathrm{B}} T$ value (where $K_{\mathrm{u}}$ is the uniaxial magnetocrystalline anisotropy, $V$ is the particle volume, $K_{\mathrm{B}}$ is the Bolzmann's constant and $T$ is the absolute temperature), which leads increasing the thermal fluctuation of magnetization [4,5]. It well know that large $K_{\mathrm{u}}$ can resist thermal fluctuation of magnetization even the particle size is very small. The $K_{\mathrm{u}}$ value of FePt alloy is as high as $7 \times 10^{7} \mathrm{erg}^{-3}$

\footnotetext{
* Corresponding author. Tel.: + 886-2-23648881; fax: + 886-223634562.

E-mail address: sscchh@ms28.hinet.net (S.-C. Chen).
}

and the saturation magnetization, $M_{\mathrm{s}}$ is about $680 \mathrm{emu}$ $\mathrm{cm}^{-3}$ [6]. According to Stoner-Wohlfarth theory, for coherent rotation in a random distribution of noninteracting particles, the coercivity is $H_{\mathrm{c}}=0.96 K_{\mathrm{u}} / M_{\mathrm{s}}$ [7], a very high $H_{\mathrm{c}}$ over $100 \mathrm{kOe}$ of FePt alloy is expected.

Current studies have been focused on magnetically hard metal nanoparticle embedded in a nonmagnetic matrix for high density magnetic recording media. High in-plane coercivity materials consisting of the face-centered-tetragonal (fct) $\mathrm{FePt}$ equiatomic $\mathrm{L}_{0}$ phase dispersed in nonmagnetic matrices have been reported in $\mathrm{FePt}-\mathrm{C}$ [8], $\mathrm{FePt}-\mathrm{SiO}_{2}$ [9], and $\mathrm{FePt}-\mathrm{Si}_{3} \mathrm{~N}_{4}$ [10] thin films. In this work, we investigate the magnetic properties and microstructure of granular $\mathrm{FePt}-\mathrm{Ag}$ thin films which have not been studied before. We find that the granular $(\mathrm{FePt})_{70}-(\mathrm{Ag})_{30}$ thin film after annealing at $600{ }^{\circ} \mathrm{C}$ for $15 \mathrm{~min}$ had in-plane coercivity $H_{\mathrm{c} / /}$ of 3.5 $\mathrm{kOe}$ and the grain size of $\mathrm{FePt}$ is about $30 \mathrm{~nm}$. It is suitable for applying in high-density magnetic recording media. The magnetic hardening mechanism of the $(\mathrm{FePt})_{70}-(\mathrm{Ag})_{30}$ thin film are also investigated. 


\section{Experimental procedure}

$(\mathrm{FePt})_{100-x}-(\mathrm{Ag})_{x}$ thin films $(x=0-50$ vol. $\%)$ were deposited on (100) silicon wafer substrates at room temperature by co-sputtering high purity $\mathrm{FePt}(99.99 \%)$ and $\mathrm{Ag}(99.99 \%)$ targets with dc magnetron sputter. The substrabe was rotated at $75 \mathrm{rpm}$ in order to attain uniform composition of the film. A $10 \mathrm{~nm}$ under layer of $\mathrm{Ag}$ and a $10 \mathrm{~nm}$ cover layer of $\mathrm{Ag}$ are used to protect the film from oxidation. The film thickness of magnetic layer is varied from 10 to $100 \mathrm{~nm}$.

The chamber base pressure was $3 \times 10^{-7}$ Torr and films were deposited under an argon pressure of 10 mTorr. The d.c. power of FePt was fixed at $40 \mathrm{~W}$ and the d.c. power of $\mathrm{Ag}$ is varied from 0 to $17 \mathrm{~W}$. The deposition rate of the FePt was about $3.3 \mathrm{~nm} \mathrm{~min}^{-1}$. The as-deposited film was sealed in quartz capsules and post-annealed in vacuum at various temperatures for 15 min, then was quenched in ice water.

The structures of the films were investigated by X-ray diffractometer (XRD) with $\mathrm{Cu}-\mathrm{K}_{\alpha}$ radiation. The film microstructure was observed by transmission electron microscopy (TEM). Thickness of the film was measured by an atomic force microscopy (AFM). Magnetic properties were measured by a vibrating sample magnetometer (VSM) and a superconducting quantum interference

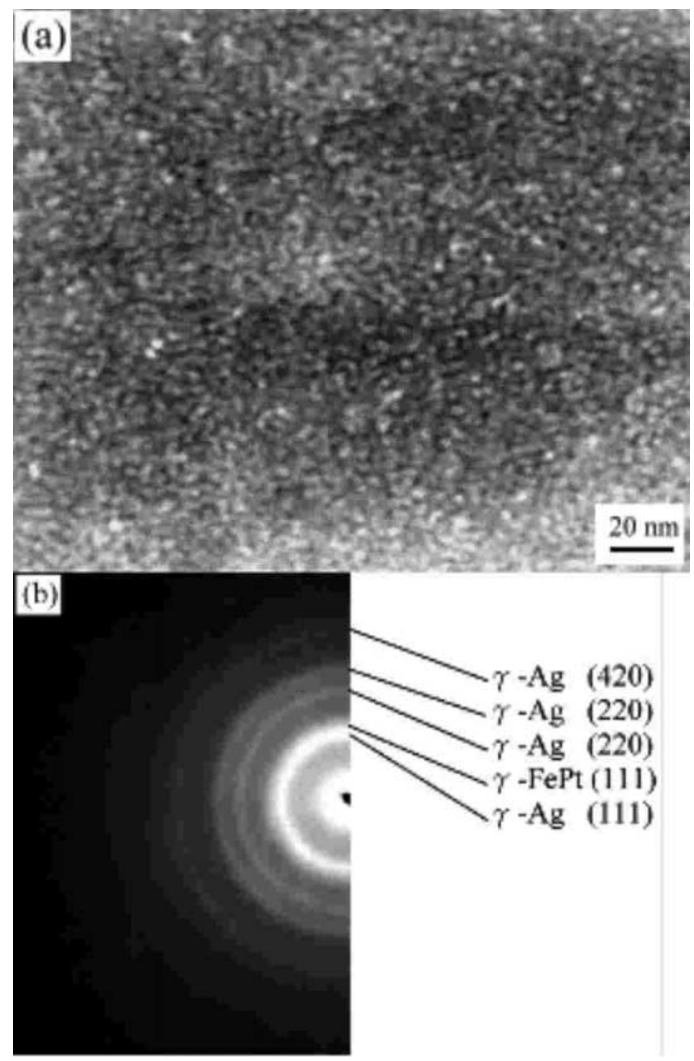

Fig. 1. TEM micrograph and electron diffraction pattern of the as-deposited $(\mathrm{FePt})_{70}-(\mathrm{Ag})_{30}$ film. (a) is the bright field image and (b) is the SAD pattern of (a).
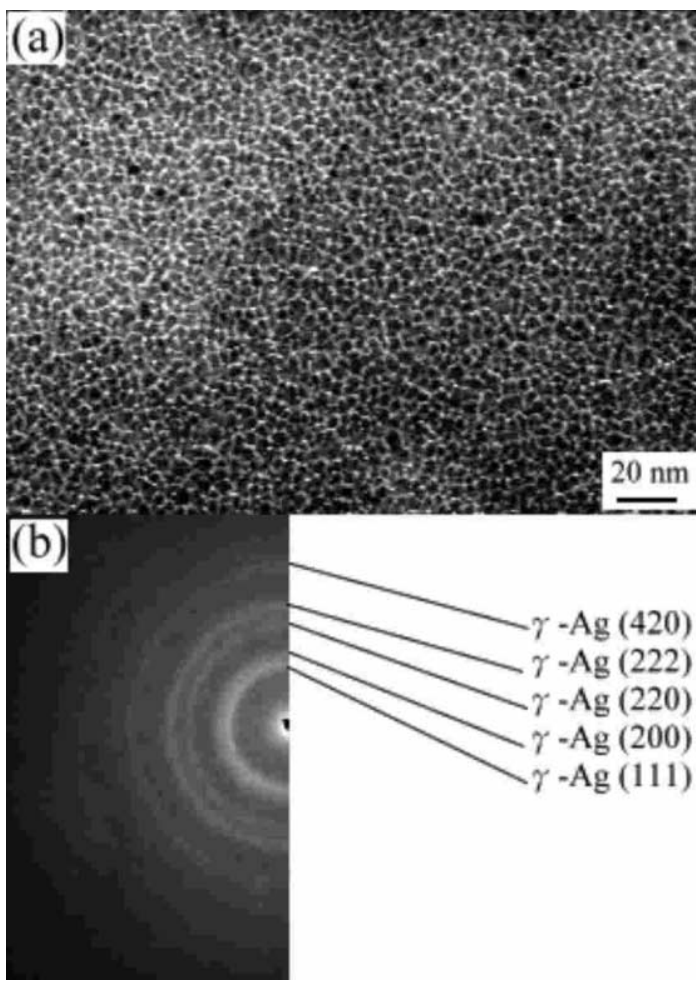

Fig. 2. TEM micrograph and electron diffraction pattern of the as-deposited pure Ag film, (a) is the bright field image, and (b) is the SAD pattern of (a). The film thickness is $10 \mathrm{~nm}$.

device (SQUID) at room temperature, with maximum applied fields were 13 and $50 \mathrm{kOe}$, respectively. The average grain size of the film was measured by the TEM bright field image. Composition and homogeneity of the film were determined by energy disperse spectrum (EDS) and the depth profiles of elements in the film were analyzed by Auger electron spectroscopy (AES).

\section{Results and discussion}

\subsection{As-deposited FePt-Ag films}

Fig. 1(a) is a TEM bright field image of the as-deposited $(\mathrm{FePt})_{70}-(\mathrm{Ag})_{30}$ film. The film thickness is 10 $\mathrm{nm}$. It shows nanocrystalline structure inside the film and the average grain size of $\mathrm{FePt}$ (white grains) is about $3 \mathrm{~nm}$. Comparing the areas of white and black grains of the TEM bright field image with the percentages of $\mathrm{FePt}$ and $\mathrm{Ag}$ within the film, it indicates that the white grain is FePt. Fig. 1(b) is the electron selected area diffraction pattern (SAD) of Fig. 1(a), it shows the structure of the as-deposited film contains not only fcc $\gamma$-FePt phase but also fcc $\gamma$-Ag phase. Fig. 2(a) and (b) are the TEM bright field image and SAD pattern of the as-deposited pure Ag film, respectively. We can see that the structure of the film is crystalline fcc $\gamma$-Ag phase 
and the grain size of the film is about $5 \mathrm{~nm}$. Its grain color is black.

Fig. 3 shows the relationships among the saturation magnetization $M_{\mathrm{s}}$, the in-plane coercivity $H_{\mathrm{c} / /}$, the outplane coercivity $H_{\mathrm{c} \perp}$ and the $\mathrm{Ag}$ content of various as-deposited $(\mathrm{FePt})_{100-x}-(\mathrm{Ag})_{x}$ films. We can see that $M_{\mathrm{s}}$ value of the pure FePt film is about $630 \mathrm{emu} \mathrm{cm}^{-3}$, and it decreases linearly as the Ag content increases. As the Ag content is up to $50 \mathrm{vol} \%, M_{\mathrm{s}}$ value of the film is decreases to $310 \mathrm{emu} \mathrm{cm}^{-3}$ that is just the $1 / 2$ of pure FePt. Since $\mathrm{Ag}$ is non-magnetic, increase of $\mathrm{Ag}$ will dilute the $M_{\mathrm{s}}$ value of the film. But $H_{\mathrm{c} / /}$ ascends

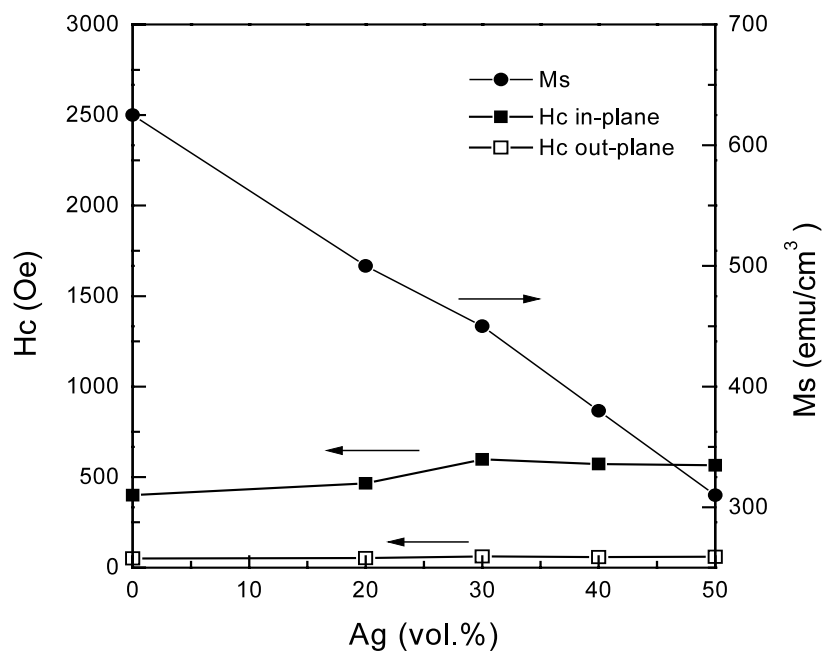

Fig. 3. The relationships among $M_{\mathrm{s}}, H_{\mathrm{c}}$, and $\mathrm{Ag}$ content of the as-deposited $(\mathrm{FePt})_{100-x}-(\mathrm{Ag})_{x}$ film. The film thickness is $10 \mathrm{~nm}$.

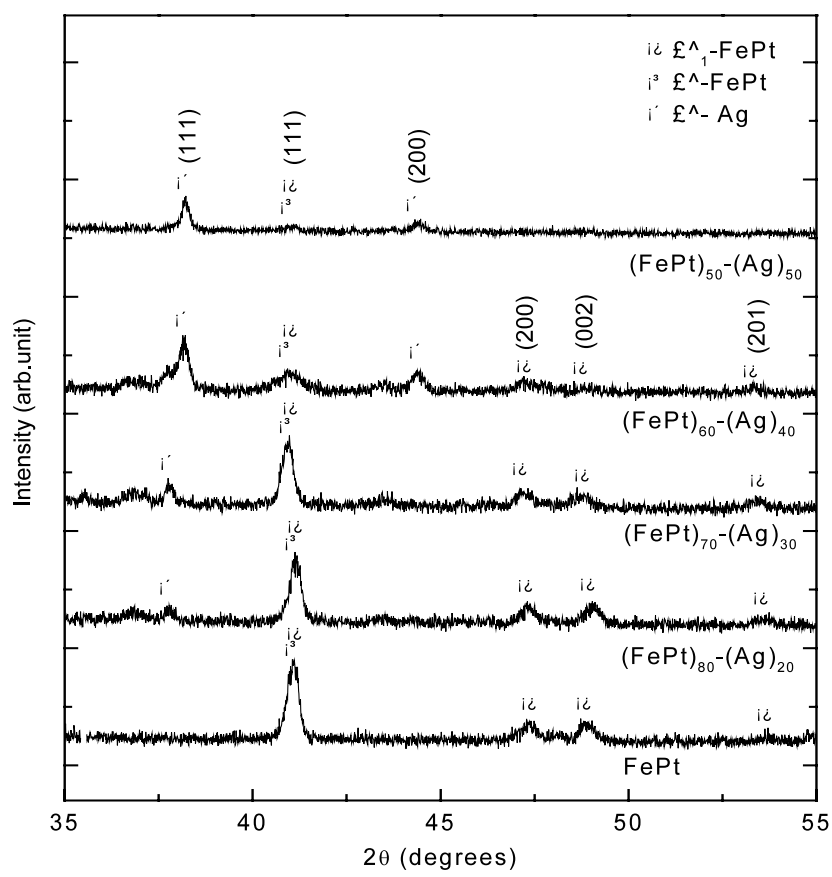

Fig. 4. XRD patterns of various $(\mathrm{FePt})_{100-x}-(\mathrm{Ag})_{x}$ thin films which annealed at $600{ }^{\circ} \mathrm{C}$ and the film thickness is $10 \mathrm{~nm}$.

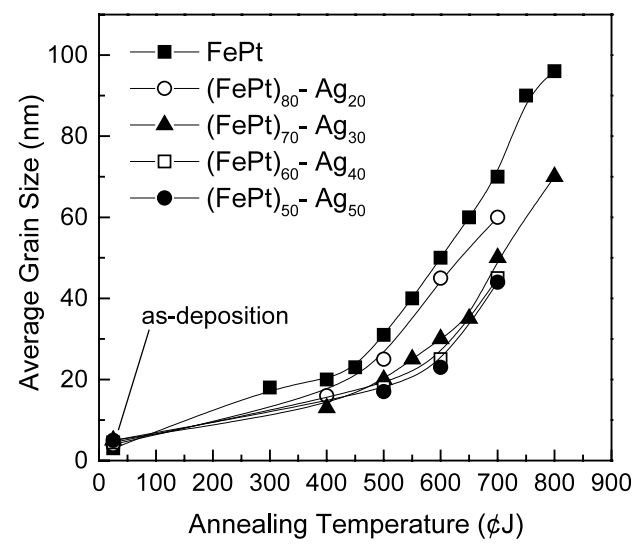

Fig. 5. Variations of average FePt grain size with annealing temperature for various annealed $(\mathrm{FePt})_{100-x}-(\mathrm{Ag})_{x}$ thin films. The film thickness is $10 \mathrm{~nm}$.

slightly as the $\mathrm{Ag}$ content rises. $H_{\mathrm{c} / /}$ value for the pure FePt film is about $400 \mathrm{Oe}$, but it will rise to about 650 $\mathrm{Oe}$ as the $\mathrm{Ag}$ content increases to $30-50$ vol.\%. The increase of $H_{\mathrm{c} / /}$ may be due to that the increase of $\mathrm{Ag}$ makes the in-plane stress of the film become larger. However, $H_{\mathrm{c} \perp}$ does not seem to be influenced by $\mathrm{Ag}$ content and keeps at about 55 Oe. Obviously, the magnetic easy-direction of the as-deposited films is parallel to the film plane. But, both $H_{\mathrm{c} / /}$ and $H_{\mathrm{c} \perp}$ of the as-deposited film are not high enough for magnetic recording media application.

\subsection{Post-annealed FePt-Ag films}

Fig. 4 is the XRD patterns of various annealed $(\mathrm{FePt})_{100-x}-(\mathrm{Ag})_{x}$ films. It shows that the intensity of the peaks of $\gamma_{1}$-FePt phase decreases as the Ag content increased. Since the thermal expansion coefficient of $\mathrm{Ag}$ is larger than that of $\mathrm{FePt}$, the increase of $\mathrm{Ag}$ content will restrain the phase transformation of $\mathrm{FePt}$ from fcc $\gamma$-phase to fct $\gamma_{1}$-phase. And we can see that annealed pure Ag film still remains the fcc structure. The shift of the peaks at higher Ag content is due to the variation of the stress within the film.

Fig. 5 shows the relationships between annealing temperature and average grain size of $\mathrm{FePt}$ in various $(\mathrm{FePt})_{100-x}-(\mathrm{Ag})_{x}$ thin films. We find that the grain sizes of FePt of all the as-deposited films are smaller than $5 \mathrm{~nm}$ but they increase rapidly with the annealing temperature. At same annealing temperature, the $\mathrm{FePt}$ grain size is decreased as $\mathrm{Ag}$ content is increased. After annealing at $600{ }^{\circ} \mathrm{C}$, the grain sizes of the pure $\mathrm{FePt}$ film, the $(\mathrm{FePt})_{70}-(\mathrm{Ag})_{30}$ film, and the $(\mathrm{FePt})_{50}-(\mathrm{Ag})_{50}$ film are 50, 30 and $20 \mathrm{~nm}$, respectively. The surrounding $\mathrm{Ag}$ represses the growth of FePt grains in the film.

Fig. 6 shows the relationships among $H_{\mathrm{c} / /}, H_{\mathrm{c} \perp}$ and the annealing temperature $T_{\text {an }}$ of various $(\mathrm{FePt})_{100-x^{-}}$ $(\mathrm{Ag})_{x}$ films. $H_{\mathrm{c} / /}$ gently rises as $T_{\text {an }}$ moves upward from 
400 to $450{ }^{\circ} \mathrm{C}$, but it climbs up promptly when $T_{\text {an }}$ is higher than $450{ }^{\circ} \mathrm{C}$. This is because the FePt transforms from the soft magnetic $\gamma$-phase to the hard magnetic $\gamma_{1}$-phase as $T_{\text {an }}>450{ }^{\circ} \mathrm{C}$. Maximum $H_{\mathrm{c} / /}$ of all the films occurs at $T_{\mathrm{an}} \approx 600{ }^{\circ} \mathrm{C}$. The maximum $H_{\mathrm{c} / /}$ is about $4.5 \mathrm{kOe}$ for pure $\mathrm{FePt}$ but it will drop to about $3.5 \mathrm{kOe}$ as $\mathrm{Ag}$ content increases to $30 \mathrm{vol} \%$. This is due to the increase of Ag content inhibits the growth of the FePt grains and makes the grains smaller and deviates from single-domain size of FePt. On the other hand, the XRD analysis reveals that the increase of Ag content would reduce the phase transformation of $\gamma$-FePt to $\gamma_{1}-\mathrm{FePt}$ phase. This can be another reason for its lower $H_{\mathrm{c} / /}$. When $T_{\mathrm{an}}>700{ }^{\circ} \mathrm{C}, H_{\mathrm{c} / /}$ drops very fast because the $(\mathrm{FePt})_{100-x}-(\mathrm{Ag})_{x}$ film takes reaction with the $\mathrm{Si}$ substrate. Fig. 7 shows the AES signal as a function of sputter time of the $(\mathrm{FePt})_{70}-(\mathrm{Ag})_{30}$ films with (a) as-deposited, (b) $T_{\text {an }}=600{ }^{\circ} \mathrm{C}$ and (c) $T_{\text {an }}=$ $750{ }^{\circ} \mathrm{C}$, respectively. The thickness of magnetic layer is $10 \mathrm{~nm}$, and both the Ag under layer and cover layer are all $10 \mathrm{~nm}$. It verifies $\mathrm{Si}$ atoms of the substrate has diffused into the magnetic layer as $T_{\text {an }}=750{ }^{\circ} \mathrm{C}$, as shown in Fig. 7(c). This explains why $H_{\mathrm{c} / /}$ decreases abruptly about $750{ }^{\circ} \mathrm{C}$ as shown in Fig. 6. The maximum $H_{\mathrm{c} \perp}$ for the as-deposited pure FePt film is about $2 \mathrm{kOe}$ at $T_{\text {an }}=600{ }^{\circ} \mathrm{C}$, but it will down to $1 \mathrm{kOe}$ as $\mathrm{Ag}$ content increases to 30 vol.\%, as show in Fig. 6. The relationships between $H_{\mathrm{c} \perp}$ and $T_{\mathrm{an}}$ have the same tendency as that of $H_{\mathrm{c} / /}$. For any $T_{\mathrm{an}}$, the $H_{\mathrm{c} \perp}$ value is always smaller than $H_{\mathrm{c} / /}$, so the magnetic easy-direction of these annealed $(\mathrm{FePt})_{100-x}-(\mathrm{Ag})_{x}$ films is parallel to the film plane. From Fig. 7, we can also see that the Fe, $\mathrm{Pt}$, and $\mathrm{Ag}$ elements distribute uniformly in the magnetic layer. For pure Ag film, the structure of the film still maintain crystalline fcc phase and the grain size is increased to about $25 \mathrm{~nm}$ after annealing at $600{ }^{\circ} \mathrm{C}$, as shown in Fig. 8.

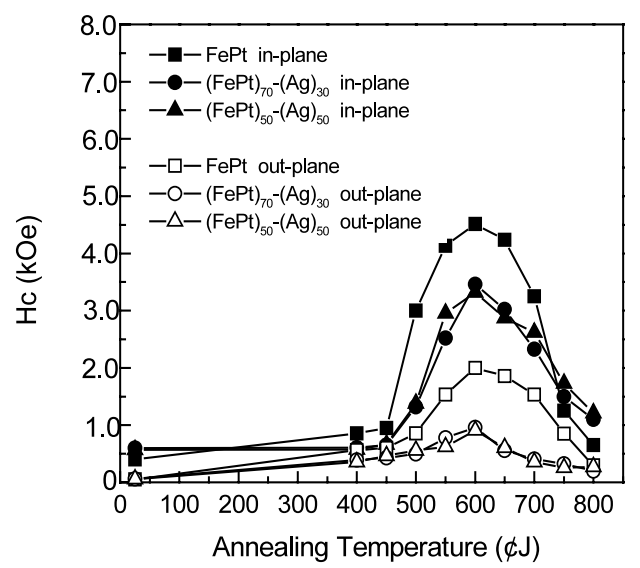

Fig. 6. Variations of $H_{\mathrm{c} / /}$ and $H_{\mathrm{c} \perp}$ with annealing temperature of various $(\mathrm{FePt})_{100-x}-(\mathrm{Ag})_{x}$ films; $\mathrm{Ag}$ contents of these films are 0, 30, and $50 \mathrm{vol} . \%$, respectively. The film thickness is $10 \mathrm{~nm}$.
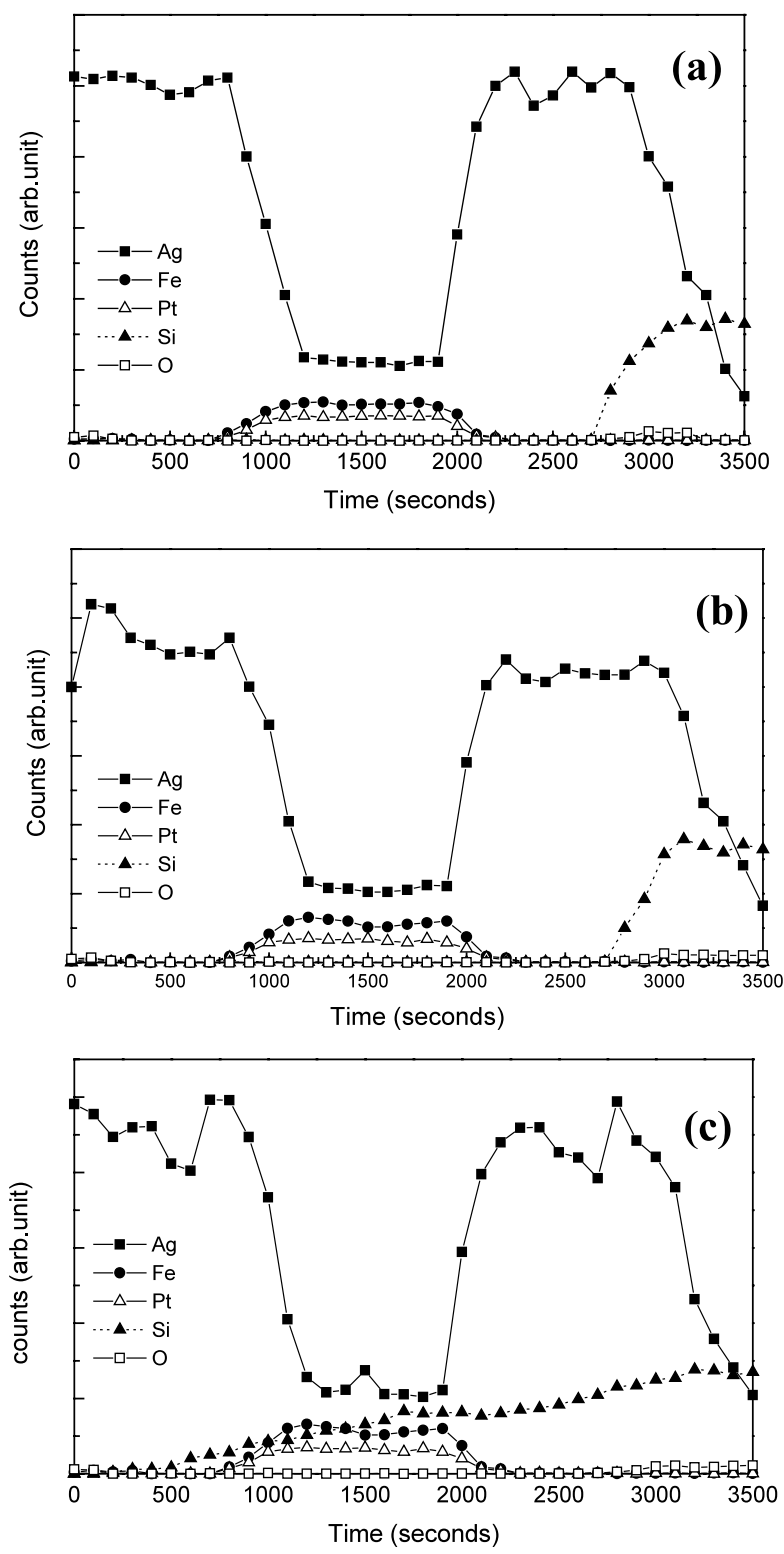

Fig. 7. AES depth profiles of the element as a function of sputter time for the $(\mathrm{FePt})_{70}-(\mathrm{Ag})_{30}$ thin films with (a) as-deposited, (b) $T_{\text {an }}=$ $600{ }^{\circ} \mathrm{C}$, (c) $T_{\text {an }}=750{ }^{\circ} \mathrm{C}$, respectively.

Fig. 9(a) is a TEM bright field image of the $(\mathrm{FePt})_{70}-$ $(\mathrm{Ag})_{30}$ film which annealed at $600{ }^{\circ} \mathrm{C}$. It shows that the magnetic FePt grains (white grains) are all surrounded by the non-magnetic Ag and well separated. This is responsible for the reduction in the interparticle interaction and thus can lower the noise of the recording medium [2,3]. The grain size of these $\mathrm{FePt}$ grains is uniform and it is about $30 \mathrm{~nm}$. Shape of the FePt particles is like rice. Fig. 9(b) is the electron diffraction pattern of Fig. 9(a), it verifies the structure of the FePt phase have transformed from $\gamma$-FePt to $\gamma_{1}$-FePt, but Ag still remains the fcc structure as that of the as-deposited film. Fig. 10 shows the $M-H$ loop of this film. We can see that its $M_{\mathrm{s}}$ value is about $350 \mathrm{emu} \mathrm{cm} \mathrm{cm}^{-3}, H_{\mathrm{c} / /}$ is about $3.5 \mathrm{kOe}$ and the squareness $\left(M_{\mathrm{r}} / M_{\mathrm{s}}\right)$ is about 0.8 . 
Fig. 11 shows the relationships among $M_{\mathrm{s}}, H_{\mathrm{c}}$, and $\mathrm{Ag}$ content in $(\mathrm{FePt})_{100-x}-(\mathrm{Ag})_{x}$ films which are annealed at $600{ }^{\circ} \mathrm{C}$. Since the increase of non-magnetic Ag will dilute $M_{\mathrm{s}}$ value of the film, $M_{\mathrm{s}}$ value of the annealed $\mathrm{FePt}-\mathrm{Ag}$ films decreases as the $\mathrm{Ag}$ content increases. $M_{\mathrm{s}}$ declines from 550 to $200 \mathrm{emu} \mathrm{cm}^{-3}$ when the $\mathrm{Ag}$ content is increased from 0 to $50 \mathrm{vol} . \%$. The $H_{\mathrm{c} / /}$ value decreases from 4.6 to $3.5 \mathrm{kOe}$ when the content of $\mathrm{Ag}$ is increased form 0 to $30 \mathrm{vol} \%$, but $H_{\mathrm{c} / /}$ value does not change distinctly when the $\mathrm{Ag}$ content is more than 30 vol.\%. The $H_{\mathrm{c} / /}$ values are 3.5 and $3.3 \mathrm{kOe}$ for 40 and 50 vol.\% $\mathrm{Ag}$, respectively. Since the increase of $\mathrm{Ag}$ content will restrain the growth of the FePt grains in the film and makes the grain size smaller and deviates from single-domain size, the $H_{\mathrm{c} / /}$ values decrease as $\mathrm{Ag}$ content is increased. However, the internal stress of the film and the interaction of the magnetic particles would also affect the $H_{\mathrm{c} / /}$ value. The change of $H_{\mathrm{c} \perp}$ with $\mathrm{Ag}$ content corresponds to the tendency of $H_{\mathrm{c} / /}$, but $H_{\mathrm{c} \perp}$ is always smaller than $H_{\mathrm{c} / /}$ no matter how much the $\mathrm{Ag}$ content is.

Fig. 12 illustrates the relationships between $\mathrm{Hc}$ values and film thickness of various $(\mathrm{FePt})_{100-x}-(\mathrm{Ag})_{x}$ films, which are annealed at $600{ }^{\circ} \mathrm{C}$. It shows both $H_{\mathrm{c} / /}$ and $H_{\mathrm{c} \perp}$ rise as the film thickness increases. Since thicker the film is, FePt grain size is larger and closer to the single domain size of the FePt grains. The grain growth

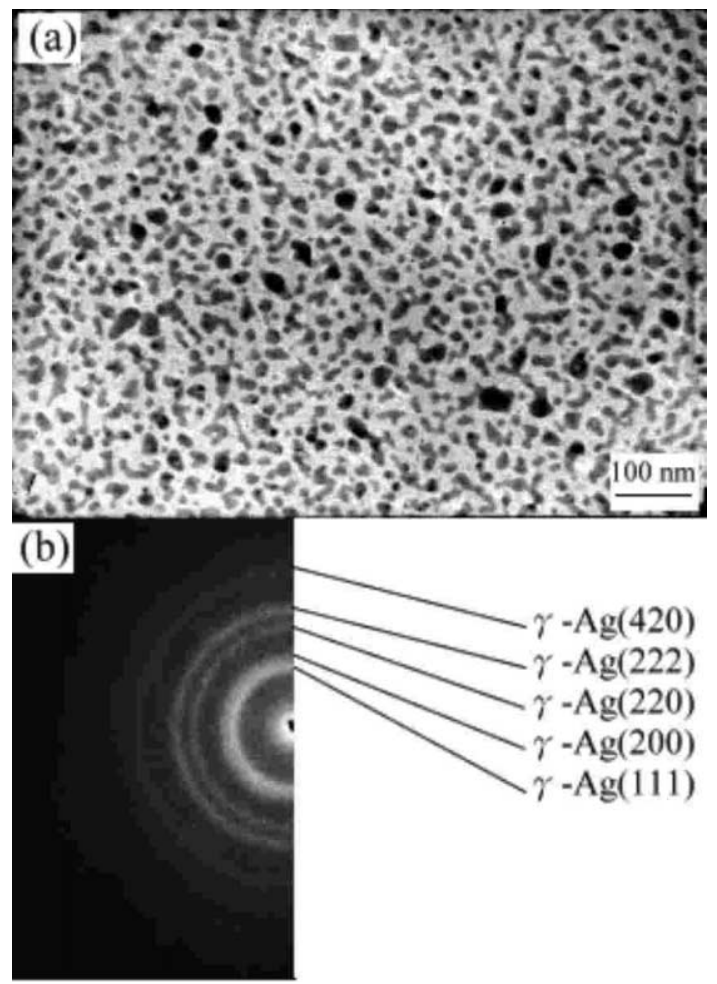

Fig. 8. (a) Is the TEM bright field image, and (b) is the SAD pattern of the pure Ag film which annealed at $600{ }^{\circ} \mathrm{C}$ for $15 \mathrm{~min}$. The film thickness is $10 \mathrm{~nm}$.
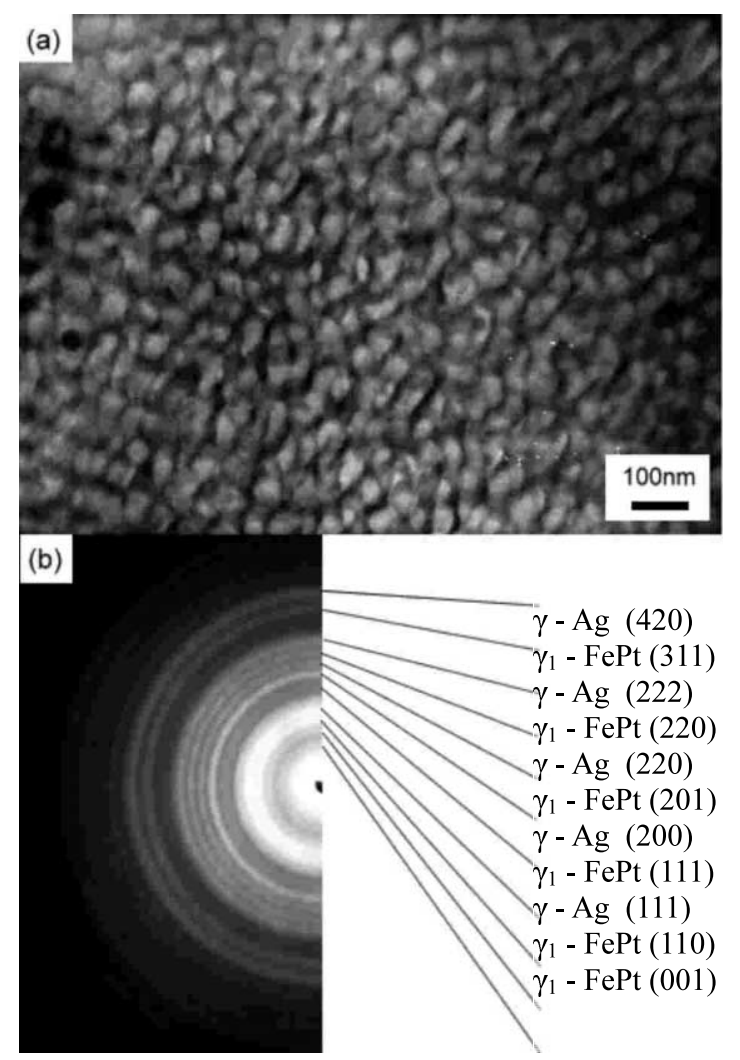

Fig. 9. (a) TEM bright field image of the $(\mathrm{FePt})_{70}-(\mathrm{Ag})_{30}$ thin film which is annealed at $600{ }^{\circ} \mathrm{C}$. (b) is the SAD pattern of the film. The film thickness is $10 \mathrm{~nm}$.

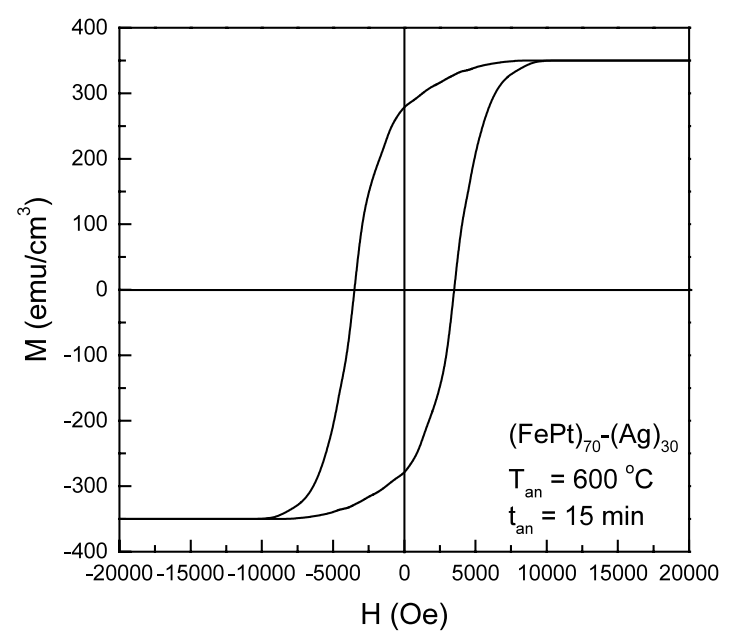

Fig. 10. The $M-H$ loop of $(\mathrm{FePt})_{70}-(\mathrm{Ag})_{30}$ thin film which is annealed at $600{ }^{\circ} \mathrm{C}$. Thickness of the film is $10 \mathrm{~nm}$.

will constrain by film thickness as grain size is larger than film thickness. For the pure FePt film, its $H_{\mathrm{c} / /}$ can reach $13 \mathrm{kOe}$ when the film thickness is $75 \mathrm{~nm}$. At this film thickness, the grain size of $\gamma_{1}-\mathrm{FePt}$ is just in the range of the single domain size, which is about $90 \mathrm{~nm}$ [6]. The $H_{\mathrm{c} / /}$ value decreases as film thickness higher than $75 \mathrm{~nm}$. This phenomenon is consistence with the 


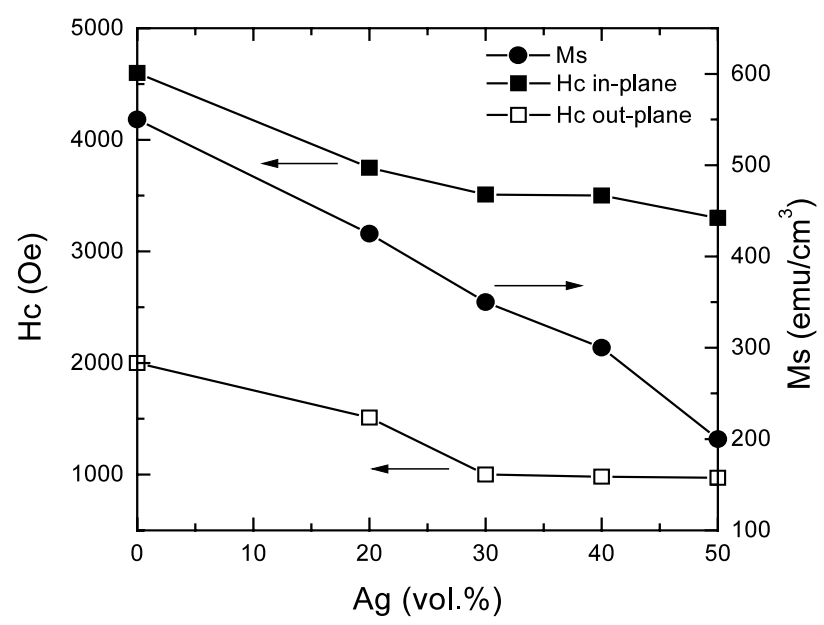

Fig. 11. The relationships among $M_{\mathrm{s}}, H_{\mathrm{c}}$, and Ag content of various annealed $(\mathrm{FePt})_{100-x}-(\mathrm{Ag})_{x}$ films. The annealing temperature is $600{ }^{\circ} \mathrm{C}$ and the film thickness is $10 \mathrm{~nm}$.

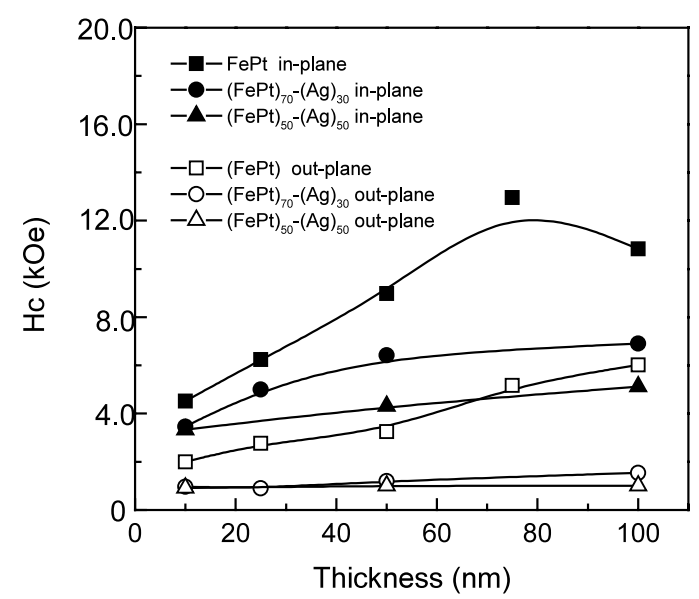

Fig. 12. Variation of $H_{\mathrm{c}}$ with film thickness of various annealed $(\mathrm{FePt})_{100-x}-(\mathrm{Ag})_{x}$ films. The film is annealed at $600{ }^{\circ} \mathrm{C}$.

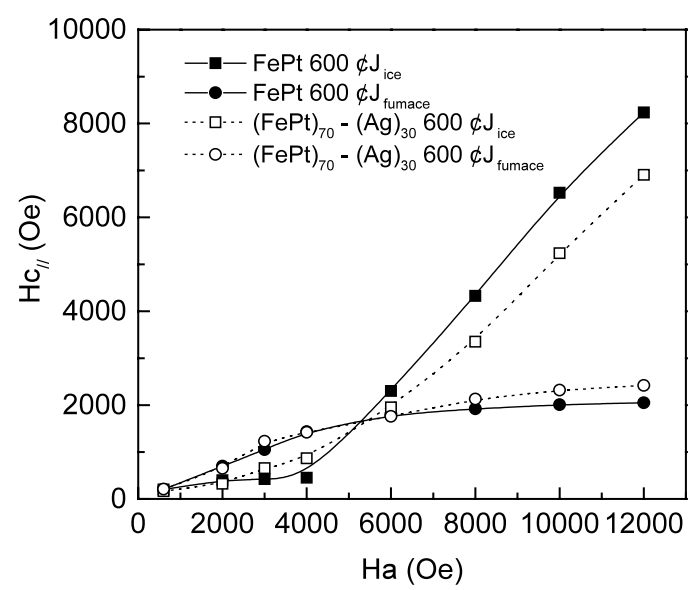

Fig. 13. $H_{\mathrm{c} / /}$ vs. $H_{\mathrm{a}}$ of various annealed $\mathrm{FePt}$ and $(\mathrm{FePt})_{70}-(\mathrm{Ag})_{30}$ thin films. The film thickness is $10 \mathrm{~nm}$. observation of Watanabe et al. [11] for pure FePt film. Both $H_{\mathrm{c} / /}$ and $H_{\mathrm{c} \perp}$ drop as the $\mathrm{Ag}$ content increases whatever the film thickness is, because the increase of Ag content will repress the grain growth and makes the phase transform from $\gamma$-FePt to $\gamma_{1}$-FePt more difficult.

Fig. 13 shows variations of the applied field $\mathrm{Ha}$ with $H_{\mathrm{c} / /}$ values of various annealed $(\mathrm{FePt})_{100-x}-(\mathrm{Ag})_{x}$ films. The annealing temperature is $600{ }^{\circ} \mathrm{C}$ and the films are furnace cooling and ice water quench after annealing, respectively. The $H_{\mathrm{c} / /}$ values are obtained from the minor loops of the VSM measurement to examine the magnetic hardening mechanism of the film. We can see that the pure FePt film quenched with iced water has the domain wall pinning mechanism, but the film slowly cooled in a furnace (with the cooling rate of $4{ }^{\circ} \mathrm{C} \mathrm{min}-1$ ) has the domain nucleation mechanism. It shows that the shape of the curve of the iced water quenched $(\mathrm{FePt})_{70}-(\mathrm{Ag})_{30}$ film is similar to that of iced water quenched pure FePt film, and the curve of the $(\mathrm{FePt})_{70}-(\mathrm{Ag})_{30}$ film cooled in a furnace is close to the pure FePt film cooled in a furnace. Distinctly, disperse FePt grains in Ag matrix does not change the magnetic hardening mechanism of the film. Excellent heat conductivity of $\mathrm{Ag}$ can be the reason to make the $(\mathrm{FePt})_{70^{-}}$ $(\mathrm{Ag})_{30}$ film dissipate heat as fast as that of the pure FePt film after heating. According to Tanaka et al. [12], anti-phase boundaries and various orientations of $\gamma_{1}$ FePt twins interfaces generate pinning sites and make the magnetic hardening mechanism of $\gamma_{1}$-FePt creates domain wall pinning mechanism. Consequently, addition of $\mathrm{Ag}$ in to FePt film has no significant influence upon the number of pinning sites.

\section{Conclusions}

Granular $\mathrm{FePt}-\mathrm{Ag}$ thin films consisting of magnetic FePt particles embedded in non-magnetic Ag matrix were successfully prepared with controlled FePt particle size and magnetic properties of the film by varying film thickness, Ag content, and annealing temperature. The in-plane coercivity was much larger than the out-plane coercivity for as-deposited and annealed films. The particle size of $\mathrm{FePt}$ in annealed film was increased with annealing temperature but decreased with increasing $\mathrm{Ag}$ content. The $(\mathrm{FePt})_{70}-(\mathrm{Ag})_{30}$ film with film thickness of $10 \mathrm{~nm}$ annealed at $600{ }^{\circ} \mathrm{C}$ for $15 \mathrm{~min}$ and ice-water quenched having an in-plane coercivity around $3.5 \mathrm{kOe}$. The $M_{\mathrm{s}}$ value of this film is about 350 $\mathrm{emu} \mathrm{cm}^{-3}$ and the squareness is about 0.8. TEM analysis exhibited that the FePt particles in this film were isolated by $\mathrm{Ag}$ and the FePt particle size was very uniform, it is about $30 \mathrm{~nm}$. This film can be used for high density magnetic recording media with low media noise. 


\section{Acknowledgements}

This work was supported by the National Science Council of ROC through Grant No. NSC 89-2216-E002-053.

\section{References}

[1] I. Kaitsu, A. Inomata, I. Okamoto, M. Shinohara, IEEE Trans. Magn. 31 (1998) 1591.

[2] R. Ranjan, J.A. Christner, D.P. Ravipati, IEEE Trans. Magn. 26 (1990) 322

[3] Y.H. Lee, J.P. Wang, L. Lu, J. Appl. Phys. 87 (2000) 6346.
[4] J.I. Gittleman, B. Abeles, S. Bozowski, Phys. Rev. B9 (1974) 3891.

[5] T. Shimatsu, J.C. Lodder, Y. Sugita, Y. Nakamura, IEEE Trans. Magn. 35 (1999) 2697.

[6] C.M. Kuo, P.C. Kuo, H.C. Wu, J. Appl. Phys. 85 (1999) 2264.

[7] B.D. Cullity, Introduction to Magnetic Materials, AddisonWesley, Reading, MA, 1972.

[8] J.A. Christodoulides, Y. Huang, Y. Zhang, G.C. Hadjipanayis, I. Panagiotopoulos, D. Niarchos, J. Appl. Phys. 87 (2000) 6938.

[9] C.P. Luo, S.H. Liou, D.J. Sellmyer, J. Appl. Phys. 87 (2000) 6941.

[10] C.M. Kuo, P.C. Kuo, J. Appl. Phys. 87 (2000) 419.

[11] M. Watanabe, T. Nakayama, K. Watanabe, T. Hirayama, A. Tonomura, Mater. Trans. JIM 37 (1996) 489.

[12] Y. Tanaka, N. Kimura, K. Hono, K. Yasuda, T. Sakurai, J. Magn. Magn. Mater. 170 (1997) 289. 